Article

\title{
Georeferencing Oblique Aerial Wildfire Photographs: An Untapped Source of Fire Behaviour Data
}

\author{
Henry Hart ${ }^{1, *}$, Daniel D. B. Perrakis ${ }^{2}\left(\mathbb{D}\right.$, Stephen W. Taylor ${ }^{2}$, Christopher Bone $^{1}$ and Claudio Bozzini ${ }^{3}(\mathbb{D}$ \\ 1 Department of Geography, University of Victoria, Victoria, BC V8P 5C2, Canada; chrisbone@uvic.ca \\ 2 Pacific Forestry Centre, Natural Resources Canada, Victoria, BC V8Z 1M5, Canada; \\ daniel.perrakis@canada.ca (D.D.B.P.); steve.taylor@canada.ca (S.W.T.) \\ 3 Swiss Federal Institute for Forest, Snow, and Landscape Research WSL, CH-8903 Birmensdorf, Switzerland; \\ claudio.bozzini@wsl.ch \\ * Correspondence: hhart4@uvic.ca
}

Citation: Hart, H.; Perrakis, D.D.B.; Taylor, S.W.; Bone, C.; Bozzini, C. Georeferencing Oblique Aerial Wildfire Photographs: An Untapped Source of Fire Behaviour Data. Fire 2021, 4, 81. https://doi.org/10.3390/ fire 4040081

Academic Editor: Wade T. Tinkham

Received: 10 August 2021

Accepted: 16 October 2021

Published: 22 October 2021

Publisher's Note: MDPI stays neutral with regard to jurisdictional claims in published maps and institutional affiliations.

Copyright: (C) 2021 by the authors. Licensee MDPI, Basel, Switzerland. This article is an open access article distributed under the terms and conditions of the Creative Commons Attribution (CC BY) license (https:/ / creativecommons.org/licenses/by/ $4.0 /)$.

\begin{abstract}
In this study, we investigate a novel application of the photogrammetric monoplotting technique for assessing wildfires. We demonstrate the use of the software program WSL Monoplotting Tool (MPT) to georeference operational oblique aerial wildfire photographs taken during airtanker response in the early stages of fire growth. We located the position of the fire front in georeferenced pairs of photos from five fires taken 31-118 min apart, and calculated the head fire spread distance and head fire rate of spread (HROS). Our example photos were taken 0.7 to $4.7 \mathrm{~km}$ from fire fronts, with camera angles of incidence from $-19^{\circ}$ to $-50^{\circ}$ to image centre. Using high quality images with detailed landscape features, it is possible to identify fire front positions with high precision; in our example data, the mean 3D error was $0.533 \mathrm{~m}$ and the maximum 3D error for individual fire runs was less than $3 \mathrm{~m}$. This resulted in a maximum HROS error due to monoplotting of only $\sim 0.5 \%$. We then compared HROS estimates with predictions from the Canadian Fire Behavior Prediction System, with differences mainly attributed to model error or uncertainty in weather and fuel inputs. This method can be used to obtain observations to validate fire spread models or create new empirical relationships where databases of such wildfire photos exist. Our initial work suggests that monophotogrammetry can provide reproducible estimates of fire front position, spread distance and rate of spread with high accuracy, and could potentially be used to characterize other fire features such as flame and smoke plume dimensions and spotting.
\end{abstract}

Keywords: wildfire modelling; fire behaviour; rate of spread; remote sensing; monophotogrammetry; WSL monoplotting tool; georeferencing; oblique aerial wildfire photography

\section{Introduction}

Fire behaviour prediction is important to operational wildfire decision-making and fire fighter safety [1]. Wildfire spread rates in conifer forests may vary from less than $1 \mathrm{~m} \cdot \mathrm{min}^{-1}$ to more than $100 \mathrm{~m} \cdot \mathrm{min}^{-1}$, while spread in grasslands and other open fuels may exceed $200 \mathrm{~m} \cdot \mathrm{min}^{-1}$ [2]. Fire spread rate relationships are used in both aspatial and spatial fire growth models and are also incorporated in risk assessments [3,4]. Observations of the position of the origin, head, flank and back of a fire over time, and the corresponding spread rates, are important for developing empirical fire behaviour models, validating any kind of fire behaviour model in real world conditions, and in wildfire cause investigations [5-7].

In the Canadian Fire Behaviour Prediction (FBP) System, for example, the predicted head fire rate of spread (HROS) is estimated using nonlinear regression relationships between observed HROS and the Initial Spread Index (ISI) of the Canadian Forest Fire Weather Index (FWI) System obtained from several hundred experimental fires and wildfires in 14 different fuel types [2-8]. While estimates of HROS from experimental fires using direct observation or indirect measures using electronic timers or imagery are most accurate $[9,10]$, such experiments are rare, and, when they do occur, are typically conducted 
during low to moderate fire danger conditions. As a result, spread measurements in high danger conditions have been mainly obtained from wildfires [11]. However, obtaining reliable wildfire observations through research or operational activities is dilemmatic. While researchers have used infrared sensors among other methods to obtain accurate wildfire observations [12,13], they face many obstacles, including difficulty in getting to incidents while notable fire activity is occurring or before suppression has influenced fire growth, or getting into favourable positions to observe fire behaviour when response actions restrict access. On the other hand, while firefighters and officers are often positioned to observe noteworthy fire behaviour, they often lack the time, training or resources to make careful observations or measurements while carrying out their main duties [14]. Thus, there is a paucity of reliable wildfire spread observations to evaluate the FBP System HROS models, or indeed all types of fire spread and growth models [15-17].

In this paper, we demonstrate a method to extract wildfire spread observations from oblique aerial photographs taken during wildfire response in the province of British Columbia, Canada. We focus on photographs that were obtained by observers in reconnaissance aircraft accompanying air tankers to document evolving fire conditions and airtanker operations early in the first burning period for training and accountability purposes. The photographs were taken at close range (less than $1 \mathrm{~km}$ ) and at varying angles, providing unobstructed views of the fire front position and flame zone depth. The use of these photos has the obvious advantage that airtankers and 'bird dog' spotter planes are in the right place at the right time, and no additional resources are required. In a previous study, Perrakis et al. [18] estimated fire spread from similar images. However, the methods used to georeference points on the photos were difficult to reproduce and contained unknown error. Therefore, our objectives in this study were as follows:

1. Develop an efficient, systematic, repeatable procedure to determine the geographic coordinates of wildfire features captured in oblique photographs.

2. Demonstrate the use of the procedure to obtain estimates of wildfire spread rates and validate fire behaviour models, using the FBP System models as an example.

To address these objectives, we investigated a novel application of a conventional photogrammetric method called monoplotting to extract fire behaviour data from oblique aerial images. Although the theory of monoplotting was first described in the early 1970s [19], its application has been limited in the past due to the lack of computing power and the availability of high resolution Digital Elevation Models (DEM) that are necessary to achieve accurate results [20]. Advances in these areas led to several monoplotting software packages, but their limited flexibility, complicated user interfaces and closed-access platforms prevented their widespread use [21]. More recently, Bozzini et al. [20] developed an openaccess monoplotting software package [22], the WSL Monoplotting Tool (MPT), at the Swiss Federal Institute for Forest, Snow and Landscape Research WSL in Birmensdorf, Switzerland that georeferences single oblique aerial images without the need for multiple, and overlapping images that are typically required for conventional photogrammetrical georeferencing practices [20]. The MPT has subsequently been used for a wide range of 3D spatial measurements and analysis, including documenting avalanches [23] and extracting ecological information from historical landscape imagery [21]. This paper extends the application of the technique to the fire behaviour context.

A brief description of the monoplotting process and its implementation in MPT are provided in Section 2. In Section 3, we document the application of the method to wildfire image series in order to calculate the spread distance and HROS of five wildfires that occurred in British Columbia, Canada between 2009 and 2014. In Section 4, we analyze the accuracy of the georeferencing process and compare the observed fire spread with predicted values. While our immediate goal was to investigate the utility and limitations of this method to obtain observations to validate HROS models within the Canadian FBP System, the method can be used to georeference oblique wildfire photographs for other fire behaviour or management applications. 


\section{Materials and Methods}

\subsection{Monoplotting Process}

Mono-photogrammetry, also known as monoplotting, is the process of georeferencing a single oblique photograph by relating it to a digital elevation model (DEM) [20]. This process involves camera calibration which provides a reconstruction of the camera parameters at the shooting time, thus allowing for matching of each point of the image with its corresponding ground point (and vice versa).

In other words, georeferencing consists of positioning the camera, the image and the DEM in such a way that, for each point on the image, the ray starting from the origin of the camera and passing through this point intersects the DEM at the corresponding ground point (Figure 1).

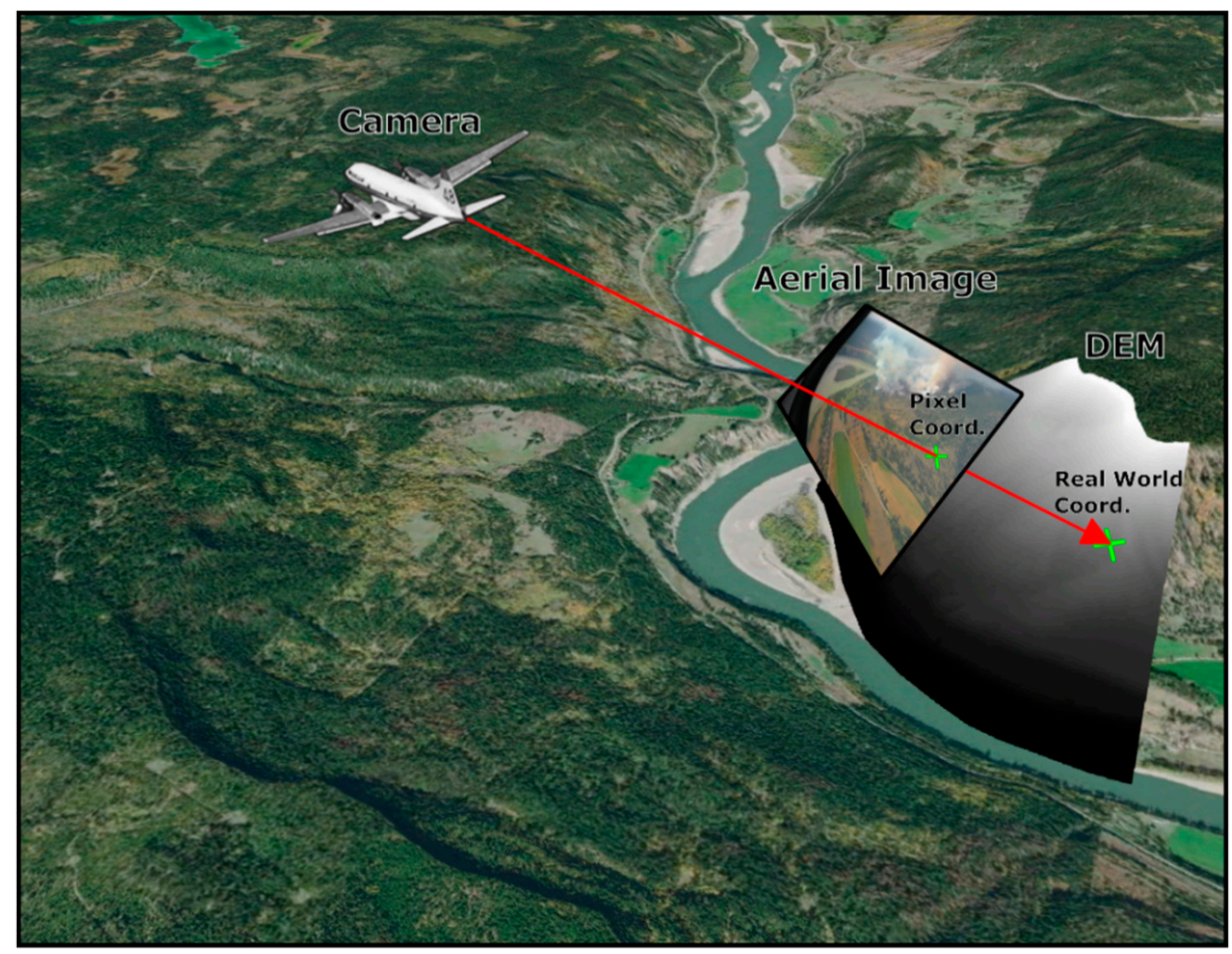

Figure 1. Monoplotting principle, displaying the relationship between the camera, photo and DEM.

A monoplotting system requires a digital image, DEM, camera system parameters and an additional georeferenced source, such as an orthoimage, from which Ground Control Points (GCPs) are determined. GCPs are points for which both the position in pixels on the image and the position in real world coordinates with respect to the DEM are known. Examples of suitable points are building corners or other stationary landscape features.

The MPT software incorporates a camera calibration algorithm, which estimates the intrinsic (image center, focal distance, radial and tangential distortion) and extrinsic (Euler rotation angle corresponding to the camera orientation, camera position coordinates) parameters of the camera system [20]. The camera calibration is an iterative process based on the method of least squares after a linearization of the collinearity equations [20], that relies on the identification of precise GCPs and high resolution input data and is essential to the success and accuracy of georeferencing digital images using MPT. As noted by Stockdale et al. [21], exact GCP placement in the 2D and 3D space, flawless DEM quality and zero film or lens distortion would result in a perfectly georeferenced image; however, this is rarely the case. Therefore, the camera calibration algorithm produces error values for each GCP pair and utilizes these values to determine the best solution of the intrinsic and extrinsic camera parameters that minimize the calculated errors using the least square 
method (Table 1). It should be noted that the calculated parameters correspond to the best configuration of the camera according to the defined points, so it is possible that some parameters (e.g., camera position, image center, etc.) do not correspond perfectly with the actual values when the photo was taken. Figure 2 visually describes the camera calibration algorithm and derivation of the error values used to calculate the final camera system parameters $[20,24,25]$.

Table 1. Summary of MPT camera calibration errors as shown in the software.

\begin{tabular}{cccc}
\hline Error & Unit & Symbol & Description \\
\hline Pixels & $\mathrm{px}$ & $\mathrm{d}$ & Distance from user defined image GCP $(\mathrm{p})$ coordinates to MPT calculated image point \\
( $\left.\mathrm{p}^{\prime}\right)$ coordinates given in pixels
\end{tabular}

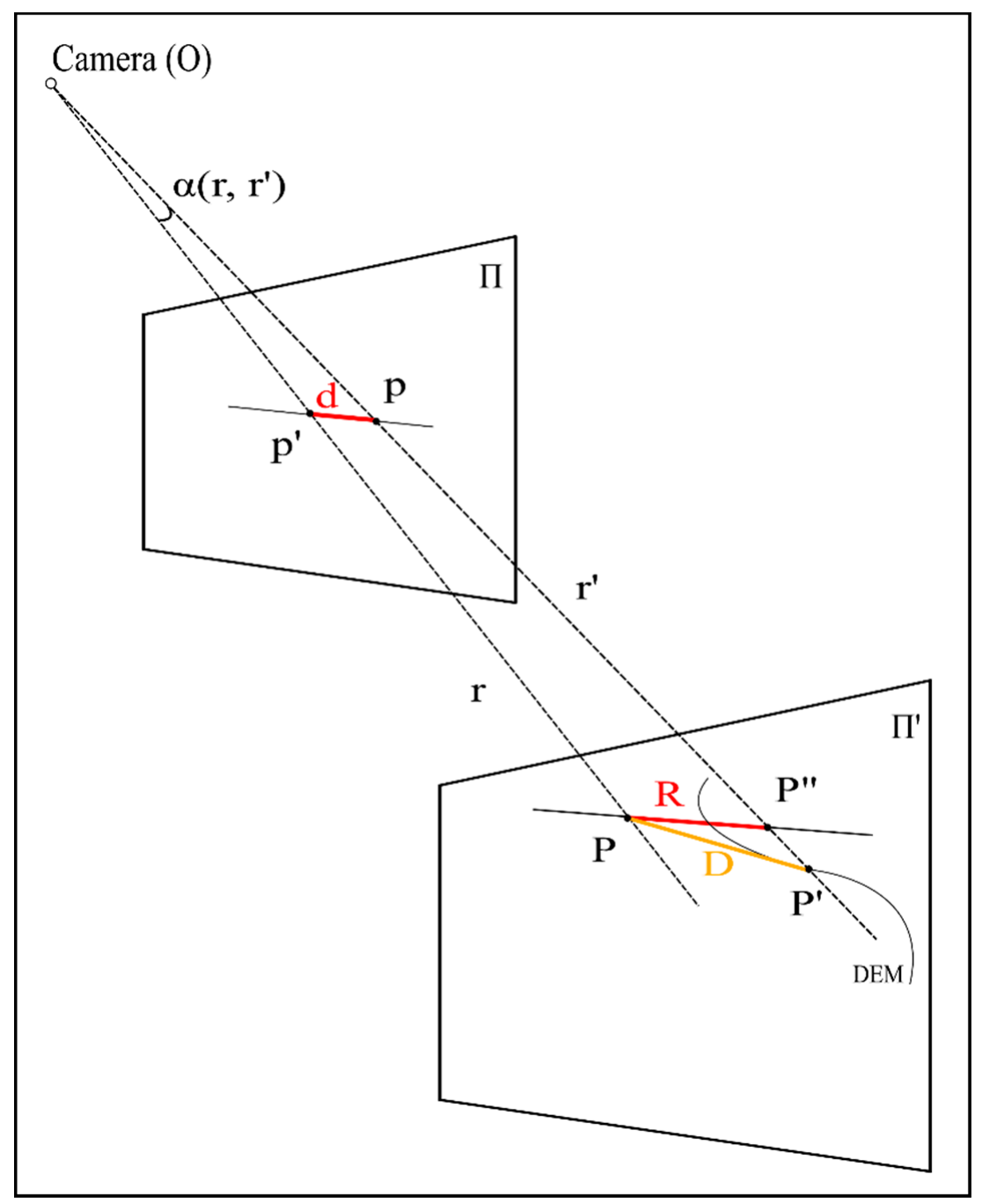

Figure 2. Visual representation of the camera calibration algorithm and derivation of error values used by MPT; figure adapted from $[21,25]$. The symbols are defined in the following paragraph and in Table 1.

During the camera calibration algorithm, the user first selects a location on the orthophoto (in combination with the DEM) to estimate the initial real-world coordinates 
of the camera position $(\mathrm{O})$ and defines a precise GCP on the image (p) and GCP on the corresponding DEM (P). Some additional elements help in evaluating the accuracy of the camera calibration. $\Pi$ is the image plane, $\Pi^{\prime}$ is a plane parallel to $\Pi$ containing $\mathrm{P}$. $\mathrm{O}$ and $\mathrm{P}$ define the ray $\mathrm{r}$, while $\mathrm{O}$ and $\mathrm{P}^{\prime}$ define $\mathrm{r}^{\prime}$. $\mathrm{p}^{\prime}$ (projection of $\mathrm{P}$ on $\Pi$ ) is the pixel point calculated from P. $\mathrm{P}^{\prime \prime}$ (intersection of $\mathrm{r}^{\prime}$ and $\Pi^{\prime}$ ) is the ground point on $\Pi^{\prime}$ calculated from $\mathrm{p}$, and $\mathrm{P}^{\prime}$ (intersection of $\mathrm{r}^{\prime}$ and the DEM) is the ground point on the DEM calculated from $\mathrm{p}$. Differences between the two rays $(\alpha)$, the MPT calculated points (d), and the user defined GCPs (R and D) represent a matrix of error types that describe the overall accuracy of the georeferencing (Table 1).

The iterative camera calibration process is based on the principle of monoplotting; more specifically, the mathematical model in which two collinearity equations are used to solve the intrinsic and extrinsic parameters of the camera system simultaneously:

$$
\begin{aligned}
& x=-c \times\left(\left(r_{11}\left(X_{P}-X_{C}\right)+r_{21}\left(Y_{P}-Y_{C}\right)+r_{31}\left(Z_{P}-Z_{C}\right)\right) /\left(r_{13}\left(X_{P}-X_{C}\right)+r_{23}\left(Y_{P}-Y_{C}\right)+r_{33}\left(Z_{P}-Z_{C}\right)\right)\right) \\
& y=-c \times\left(\left(r_{12}\left(X_{P}-X_{C}\right)+r_{22}\left(Y_{P}-Y_{C}\right)+r_{32}\left(Z_{P}-Z_{C}\right)\right) /\left(r_{13}\left(X_{P}-X_{C}\right)+r_{23}\left(Y_{P}-Y_{C}\right)+r_{33}\left(Z_{P}-Z_{C}\right)\right)\right)
\end{aligned}
$$

where $\mathrm{x}, \mathrm{y}$ are image coordinates; $\mathrm{c}$ is the focal length; $\mathrm{X}_{\mathrm{C}}, \mathrm{Y}_{\mathrm{C}}$ and $\mathrm{Z}_{\mathrm{C}}$ are the real world coordinates of camera position; $r_{11}-r_{33}$ are the coefficients of the rotation matrix defining the camera rotation parameters; and $X_{P}, Y_{P}$ and $Z_{P}$ are the known coordinates of the GCP $[20,26]$. Once the camera system parameters are estimated, the correspondence between image and ground points are determined by MPT using Equations (1) and (2) and the DEM (the DEM is needed for calculation from pixel to real coordinates).

\subsection{Study Area, Image Selection and Data Compilation}

The BC Wildfire Service (BCWS) has the primary responsibility to manage wildfires in the province of British Columbia, Canada. On average, 1600 fires occur each year in the province within a land area of about 94 million ha [27]. Airtankers are used in an initial attack on an average of $15 \%$ of fires in $\mathrm{BC}$ when fire behaviour is beyond ground crew capacity, or to initiate initial attack when the arrival of ground crews is delayed. BCWS Air Attack Officers, who carry out an initial assessment from reconnaissance aircraft and guide the air tankers towards the fire, take digital photographs of each incident to document the fire behaviour and air tanker effectiveness. Photographs are typically captured with consumer-grade hand-held cameras or smartphones (more recent images are of increasing quality). Digital images acquired since 2000 are archived in a central database.

We selected ten images from five wildfires in the BCWS archive that occurred between 2009 and 2014 (Figure 3) within a wide range of landscape features and vegetation types (Table 2). The selected photographs contained a suitable perspective of the fire front location in successive images separated by at least $30 \mathrm{~min}$, as well as landscape features suitable for georeferencing (Figure 4).

As noted in Section 2.1, in order to georeference the photographs, the monoplotting procedure requires GCPs visible in both the oblique photographs and in an orthoimage, and a digital elevation model (DEM) [24]. We obtained a $25 \mathrm{~m}$ DEM from the British Columbia Data Catalogue and orthoimages, all of which are under $0.5 \mathrm{~m}$ resolution, from various satellite sources within the ESRI World Imagery layer [28,29]. The wildfire photographs and orthoimages associated with each fire site are shown in Figure 4. Although the orthoimages for Sites 1, 2, 4 and 5 were captured after the fires had occurred, the GCPs were not affected by the fires. 


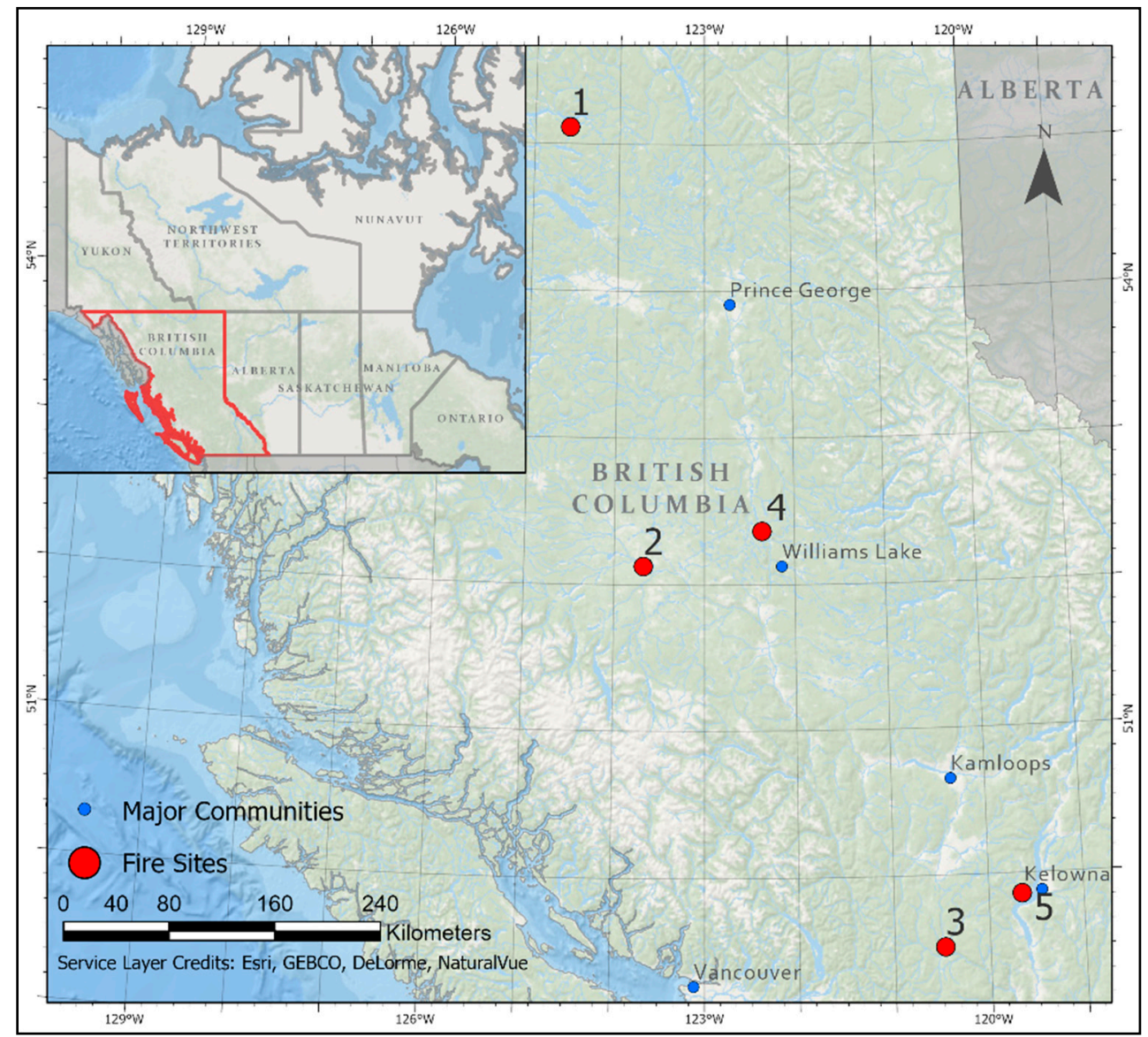

Figure 3. The location of the fire sites used in this study in British Columbia.

Table 2. Study Site descriptions, including landscape features and vegetation descriptions.

\begin{tabular}{|c|c|c|}
\hline Site Number & Landscape Features & Vegetation Type \\
\hline 1 & Flat riparian landscape, open areas with shrubs, patchy forest & Engelmann spruce-Subalpine fir forest \\
\hline 2 & $\begin{array}{c}\text { Flat landscape, two building structures, open areas with shrubs, } \\
\text { forest and agricultural areas }\end{array}$ & Ponderosa Pine-Douglas-fir \\
\hline 3 & $\begin{array}{c}\text { Moderately sloped landscape, open grass field with lone } \\
\text { standing trees }\end{array}$ & Interior grassland, cured \\
\hline 4 & $\begin{array}{l}\text { Steeply sloped landscape, two buildings, patchy forested sections } \\
\text { with lone standing trees }\end{array}$ & $\begin{array}{l}\text { Grassland-Ponderosa pine } \\
\text { forest transition }\end{array}$ \\
\hline 5 & $\begin{array}{l}\text { A: Moderately sloped landscape, many buildings, sports fields, } \\
\text { forested areas } \\
\text { B: Moderately sloped landscape, two buildings, densely forested with } \\
\text { open disturbance patches }\end{array}$ & Closed Douglas-fir forest \\
\hline
\end{tabular}




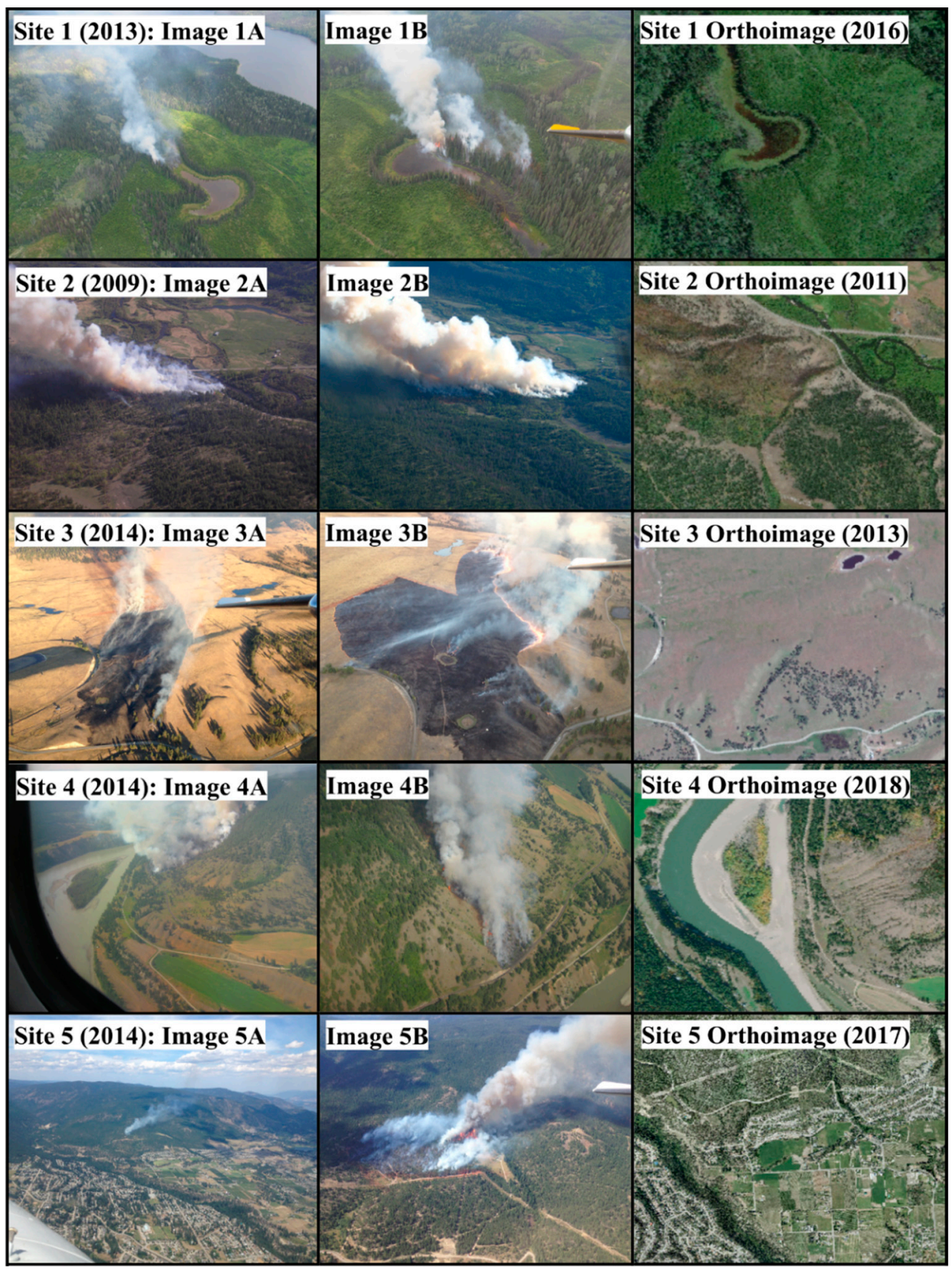

Figure 4. Study site image pairs with their respective orthoimages. Images were captured at the following Pacific Daylight times: 1A 14:31, 1B 15:13, 2A 18:16, 2B 19:13, 3A 18:33, 3B 19:04, 4A 14:56, 4B 16:09, 5A 13:48 and 5B 15:46.

\subsection{Georeferencing Oblique Aerial Wildfire Images Using MPT}

After assembling the oblique photo pairs, orthophotos and DEM for each site, we selected 5 GCPs in each photo pair that could also be located in the corresponding orthophoto. To work effectively, GCPs need to be located in a dispersed pattern across the oblique photos; when this is not possible, it is necessary at least to find the required control points around the feature or features of interest in the $[21,23,25]$ - in this case, the fire front position. As suggested by Stockdale et al. [21], we avoided using GCPs on hill tops or terrain breaks where there is a higher risk of points being displaced across large horizontal distances (e.g., infinitely beyond the horizon line or on a mistaken hill peak beyond the correct one). In addition, GCPs should be located close to the features of interest, as precision decreases with distance from the camera. We note that it is not necessary that the 
same GCPs be used in the successive images. We evaluated the accuracy of each selected GCP and adjusted or replaced those with unacceptable accuracy where possible. GCPs consisted primarily of individual identifiable trees, shrubs and building corners (Table 2). A GCP was considered acceptable if it had a three-dimensional error (World 3D Error) less than $5 \mathrm{~m}$ (i.e., the distance from MPT calculated GCP to the user defined GCP in real-world space; Table 1). Furthermore, following Bozzini [24], the GCP must have an angle error less than or near $0.01^{\circ}$. Examples of GCPs with low error values are shown in Figure 5.

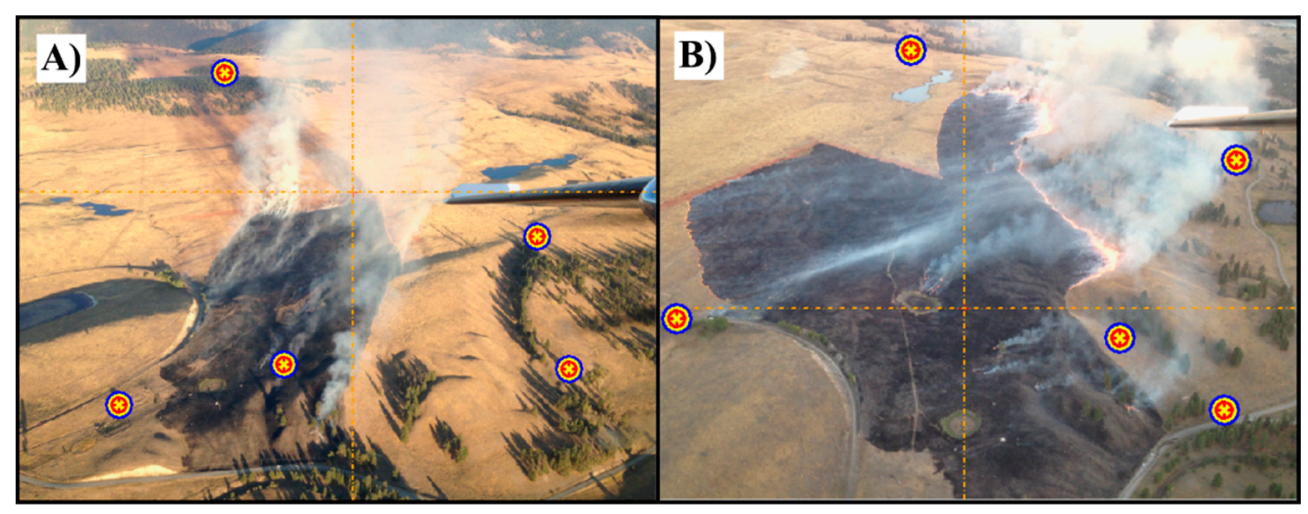

Figure 5. Overlapping user defined (yellow X's), MPT computed GCPs (blue circles) and computed image centre (dotted line crosshairs) displaying successfully calibrated wildfire images for Site 3 : image 3A (A) and 3B (B).

Before determining the headfire position and HROS, we extracted the angle of incidence of each image using their respective viewshed parameters and the real-world coordinates of the image centre. Specifically, we calculated the angle between a ray from the camera centre and the slope of a $10 \mathrm{~m}$ segment of ground at the image centre [21].

\subsection{Headfire Position Interpretation and Rate of Spread Calculation}

Our aim was to determine the Head Fire Spread Distance (HSD) and HROS in successive images. In order to make meaningful interpretations of HROS from HSD, images must be selected where the fuels and topography are relative uniform between the successive fire front positions. After georeferencing the digital images, we used the annotation feature in MPT to digitize custom georeferenced vectors (polylines) on the digital image to represent the fire front position. The head of a fire typically develops a curved front due to the distribution of radiation ahead of the fire [30]. Where fire growth is approximated by the elliptical model [31], the apex of the ellipse represents the head of the fire. Thus, there is a point (the head) at the fire front where the HROS (and so the fireline intensity, flame length and flame zone depth) are at a maximum, and the flame tilt towards the unburned fuel is also at a maximum [32]. The location of the head fire (front) was determined visually, based on the shape of the fire perimeter, the flame zone depth, flame height, angle and smoke direction, when they could be observed (Figure 6). For the purpose of estimating HROS, only the furthest leeward segments of fireline are required; in certain cases (e.g., Figure 6B), fire suppression actions or fuel discontinuities may determine which segments of fireline produce subsequent fire growth.

The fire front positions were exported from MPT as individual shapefiles and imported into ArcPro (ESRI, Redlands, CA, USA). The HSD was calculated using the 'Near' tool, as the Euclidian distance between the heads on successive arcs and can be seen as the perpendicular Hausdorff distance between two successive curves (the maximum of all minimum distances between two curves). The HSD is typically normal to the head fire front [32] (and the head fire front is typically normal to the spread direction). In cases when it is difficult to identify the head based on flame zone properties, we estimated the position 
in relation to the smoke column base, tilt angle, and spread direction. Using the HSD, we then estimated the headfire rate of spread as:

$$
\mathrm{HROS}=\mathrm{HSD} /(\mathrm{T} 2-\mathrm{T} 1)
$$

where HSD is the head fire spread distance and T1 and T2 are the times of photo capture. To demonstrate the use of the data to validate fire spread models, we determined the vegetation and FBP System fuel type associated with each fire from the BC Forest Service's vegetation resource inventory (VRI) data and fuel type layer [33] and obtained fire weather information from weather station data. See the Appendix A for more information on the FBP System HROS predictions.

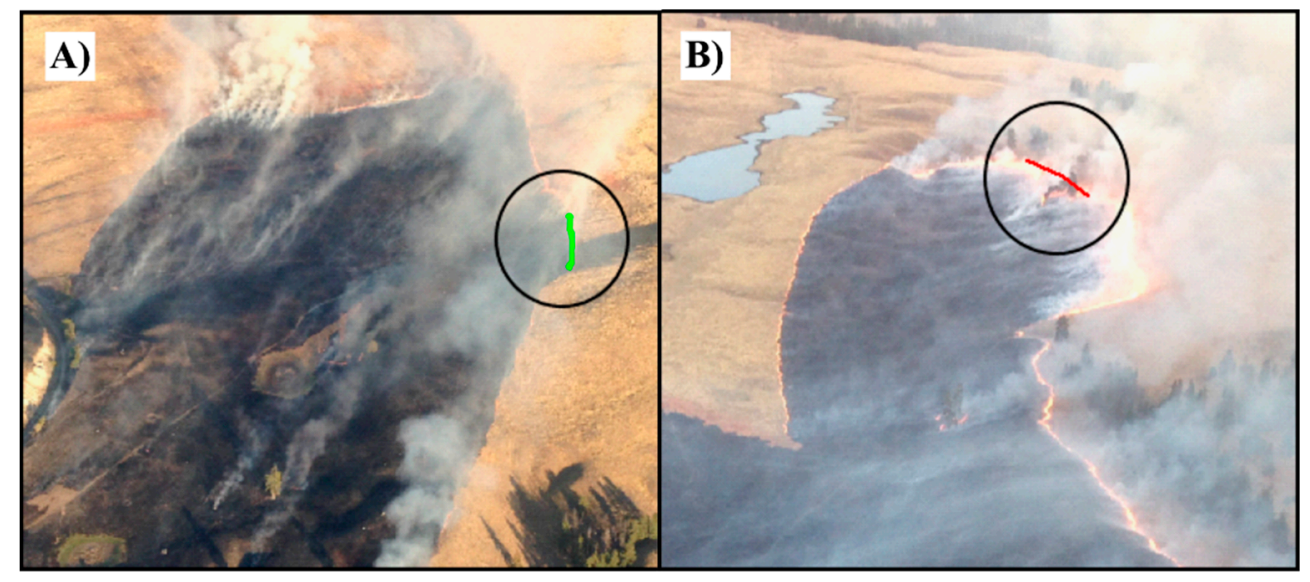

Figure 6. (A) Start fire front position (green line); (B) end fire front position (red line) at Site \#3.

\section{Results}

\subsection{Fire Front Locations and Accuracy Assessment}

We used the monoplotting technique to estimate the position of fire fronts in 10 images of five fires in British Columbia. The estimated position of the fire fronts and the GCPs used to georeference each image are shown in Figure 7. The positional accuracy of the fire front locations (or of other features) depends greatly on the error in GCP locations and the camera angle of incidence. The error values of the GCPs for each image are shown in Table 3.

Table 3. The GCP errors for each georeferenced wildfire image.

\begin{tabular}{cccccc}
\hline Image \# & $\begin{array}{c}\text { Aerial Image } \\
\text { Time Stamp }\end{array}$ & $\begin{array}{c}\text { Mean Angle } \\
\text { Error }\left({ }^{\circ}\right)\end{array}$ & $\begin{array}{c}\text { 3D Error } \\
(\mathbf{m}) \text { Min. }\end{array}$ & $\begin{array}{c}\text { 3D Error } \\
(\mathbf{m}) \text { Max. }\end{array}$ & $\begin{array}{c}\text { 3D Error } \\
(\mathbf{m}) \text { Mean }\end{array}$ \\
\hline 1A & $14: 31$ & 0.008 & 0.033 & 0.388 & 0.244 \\
1B & $15: 13$ & 0.011 & 0.033 & 0.382 & 0.253 \\
2A & $18: 16$ & 0.009 & 0.053 & 1.034 & 0.600 \\
2B & $19: 13$ & 0.002 & 0.087 & 0.822 & 0.500 \\
3A & $18: 33$ & 0.001 & 0.137 & 1.127 & 0.555 \\
3B & $19: 04$ & 0.001 & 0.102 & 0.672 & 0.322 \\
4A & $14: 56$ & 0.009 & 0.327 & 0.691 & 0.475 \\
4B & $16: 09$ & 0.012 & 0.234 & 0.962 & 0.706 \\
5A & $13: 48$ & 0.014 & 0.133 & 2.030 & 1.197 \\
5B & $15: 46$ & 0.011 & 0.103 & 0.959 & 0.477 \\
\hline Mean or Extreme & NA & 0.008 & 0.033 & 2.030 & 0.533 \\
\hline
\end{tabular}




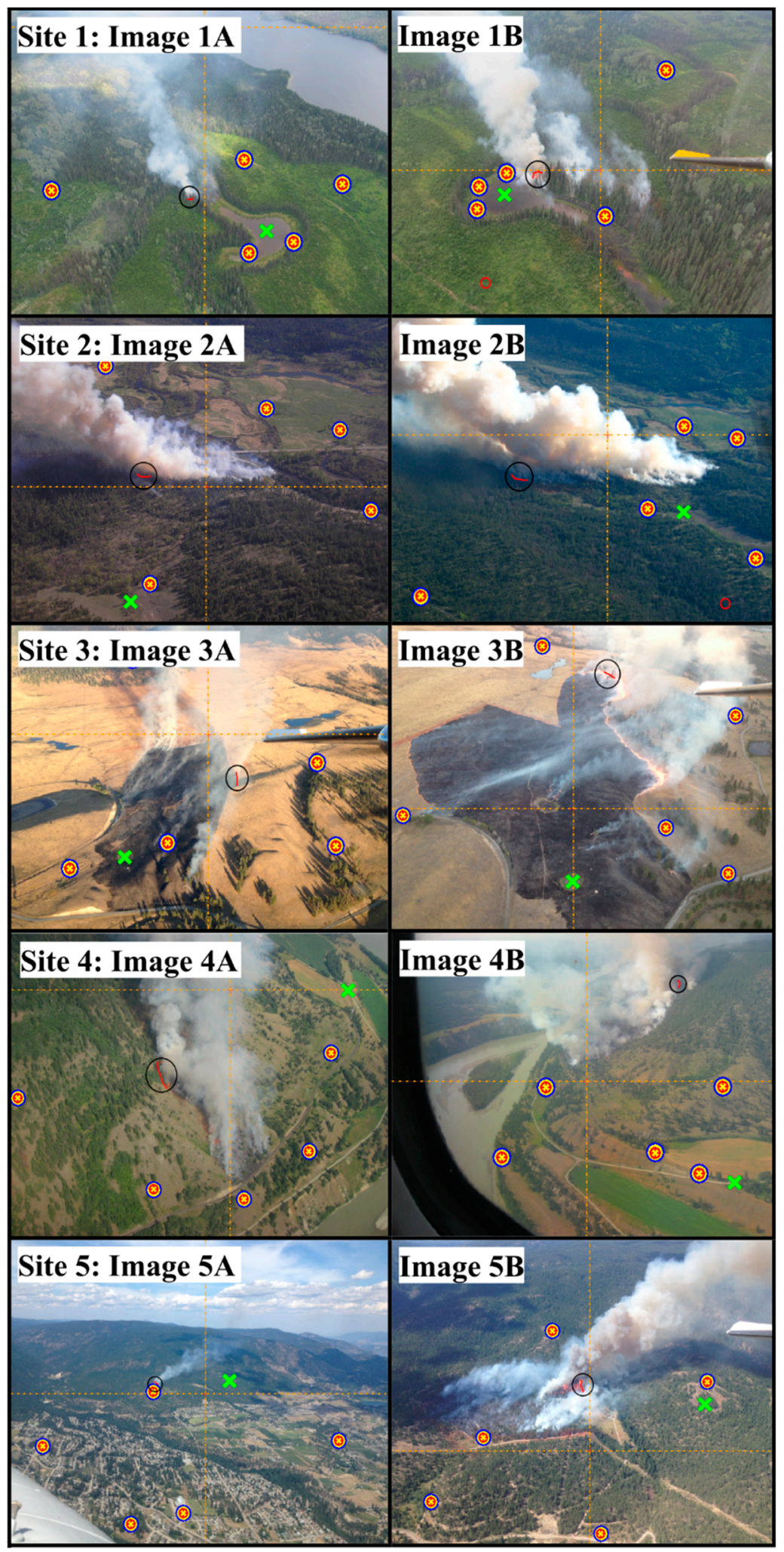

Figure 7. Georeferenced photographs, with identified GCPs (targets), fire front positions (red line in black circle) and green ' $X$ ' representing a reference feature visible in both images.

The mean and maximum 3D error of each of the five image pairs were all under the initial requirement of less than $5 \mathrm{~m}$ indicating successful georeferencing. Six of the images also met the angle error target of less than $0.01^{\circ}$, with the remaining four images not exceeding $0.014^{\circ}$, which we considered to be within a reasonable range. 
The distance to fire front, elevation above ground level and camera angle of incidence all vary from image to image (Table 4). The azimuth of each camera direction is provided for clarity.

Table 4. The estimated camera characteristics for each georeferenced image.

\begin{tabular}{ccccc}
\hline Image \# & $\begin{array}{c}\text { Approx. Distance } \\
\text { to Fire Front }(\mathbf{m})\end{array}$ & $\begin{array}{c}\text { Elevation above } \\
\text { Ground Level }(\mathbf{m})\end{array}$ & $\begin{array}{c}\text { Angle of } \\
\text { Incidence }\left(^{\circ}\right)\end{array}$ & Azimuth $\left({ }^{\circ}\right)$ \\
\hline 1A & 1040 & 587.63 & -42.02 & 85.44 \\
1B & 650 & 360.16 & -43.40 & 290.86 \\
2A & 1725 & 836.29 & -31.95 & 205.09 \\
2B & 3720 & 1443.46 & -25.67 & 224.78 \\
3A & 1720 & 794.27 & -36.32 & 114.35 \\
3B & 2130 & 516.12 & -42.52 & 153.80 \\
4A & 1275 & 1024.43 & -49.52 & 104.10 \\
4B & 2420 & 631.57 & -31.54 & 332.08 \\
5A & 4665 & 810.97 & -18.82 & 11.80 \\
5B & 1575 & 772.71 & -37.09 & 352.91 \\
\hline Mean & 2092 & 777.76 & -35.89 & NA \\
\hline
\end{tabular}

The distance to fire front, camera elevation and angle of incidence ranged between 650 to $4665 \mathrm{~m}, 365$ to $1443 \mathrm{~m}$ and -18 to $-49^{\circ}$, respectively. There was a significant correlation between the angle of incidence and the 3D accuracy $\left(\mathrm{r}^{2}=0.63\right)$ but no significant relationship between angle of incidence and angle error (Figure 8).

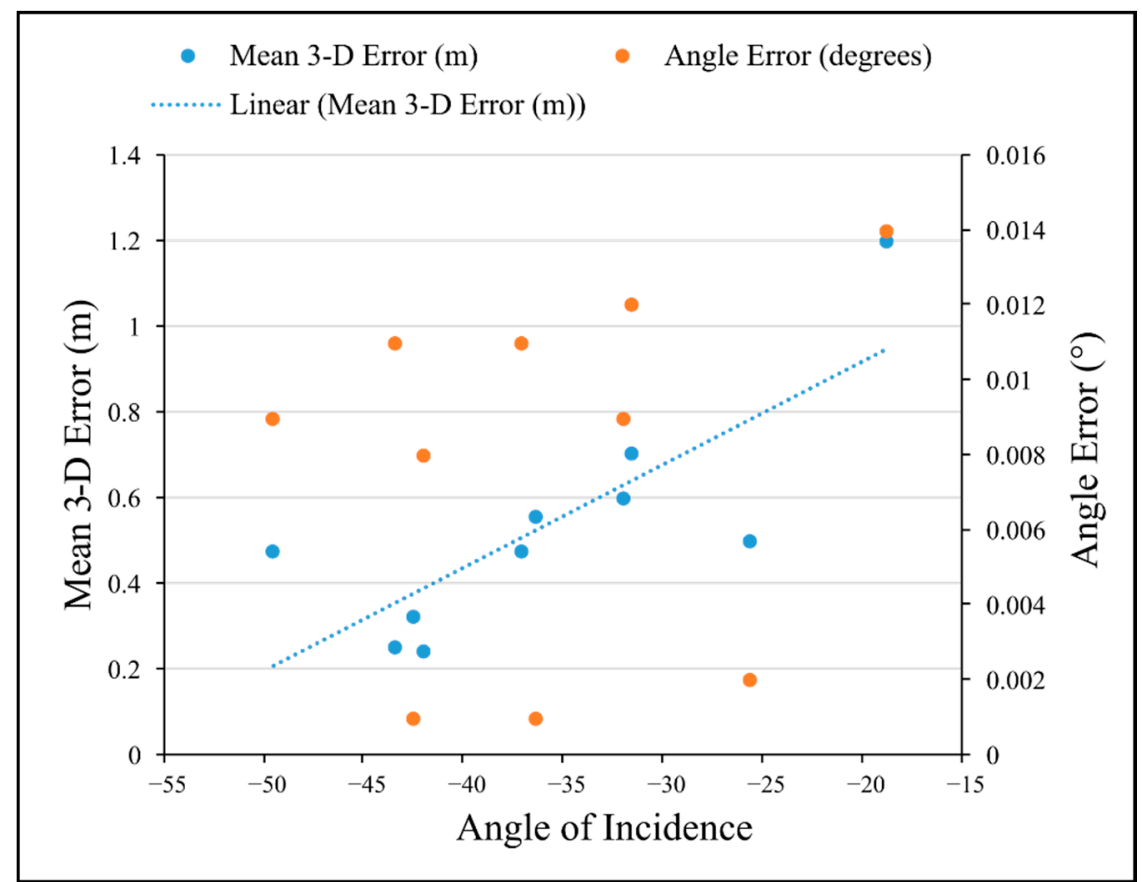

Figure 8. Relationship between angle of incidence and mean 3D error, and angle error in 10 wildfire images.

\subsection{Fire Spread Distance and Rate Estimates}

Spread distances and HROS (Equation (3)) are shown in Table 5. Spread distances ranged from 201 to $846 \mathrm{~m}$ over burning periods of 31 to $118 \mathrm{~min}$, resulting in HROS values from 4.7 to $27.3 \mathrm{~m} \cdot \mathrm{min}^{-1}$. The max total 3D error refers to the sum of the maximum 3D error of each GCP (provided by MPT software) of both images. The max HROS error refers to the maximum possible error associated each Site due to monoplotting and is calculated by dividing the max total 3D error by fire spread distance. 
Table 5. Fire behaviour parameters determined from the georeferenced wildfire images.

\begin{tabular}{ccccccc}
\hline Site \# & Fire Year & $\begin{array}{c}\text { Fire Spread } \\
\text { Distance }(\mathbf{m})\end{array}$ & $\begin{array}{c}\text { Burning Period } \\
(\mathbf{m i n})\end{array}$ & $\begin{array}{c}\text { Max Total 3D } \\
\text { Error }(\mathbf{m})\end{array}$ & $\begin{array}{c}\text { Max HROS Error } \\
(\mathbf{\%})\end{array}$ & $\begin{array}{c}\text { HROS } \\
(\mathbf{m} \cdot \mathbf{m i n}-\mathbf{1})\end{array}$ \\
\hline 1 & 2013 & 200.63 & 42 & 0.770 & 0.38 & 4.78 \\
2 & 2009 & 581.13 & 57 & 1.856 & 0.32 & $10.20^{\mathrm{a}}$ \\
3 & 2014 & 845.77 & 31 & 1.799 & 0.21 & 27.28 \\
4 & 2014 & 377.42 & 73 & 1.653 & 0.44 & 5.17 \\
5 & 2014 & 554.30 & 118 & 2.989 & 0.54 & 4.70 \\
\hline
\end{tabular}

a See Appendix A for a recalculation of Site 2 based on a different starting segment.

We calculated the rate of spread predicted by the FBP System using the closest-match FBP System fuel type for each fire, and the weather indices from interpolated surfaces [34]. The differences between the rate of spread in the oblique photos and the predicted spread ranged between 1.0 to $6.10 \mathrm{~m} \cdot \mathrm{min}^{-1}$ with a \% difference RMSE of 4.258 (Table 6). For Site 2, the calculations were repeated using an initially unidentified spot fire (see below), which reduced the fire spread distance considerably, improving the fit between observed and predicted HROS. Details are provided in the Appendix A.

Table 6. The observed and FBP System predicted fire spread rates for the fire behaviour parameters from the georeferenced wildfire imagery. $\mathrm{HROS}_{\mathrm{p}}$ and $\mathrm{HROS}_{\mathrm{O}}$ refer to predicted and observed rate of spread. See the Appendix A for FBP System calculation details.

\begin{tabular}{cccccc}
\hline Fire Obs. \# & $\begin{array}{c}\text { FBP Fuel } \\
\text { Type }\end{array}$ & $\begin{array}{c}\text { HROS }_{\mathbf{p}} \\
\left(\mathbf{m} \cdot \mathbf{m i n}^{-\mathbf{1}} \mathbf{)}\right.\end{array}$ & $\begin{array}{c}\text { HROS }_{\mathbf{O}} \\
\left(\mathbf{m} \cdot \mathbf{m i n}^{-\mathbf{1}}\right)\end{array}$ & $\begin{array}{c}\text { Difference } \\
\left(\mathbf{m} \cdot \mathbf{m i n}^{-\mathbf{1}}\right)\end{array}$ & $\begin{array}{c}\text { Difference } \\
\mathbf{( \% )}\end{array}$ \\
\hline 1 & C-2, C-3 & 5.80 & 4.78 & +1.02 & 21.33 \\
2 & C-7 & 4.10 & 10.20 & -6.10 & $-59.80^{\mathrm{a}}$ \\
3 & O1-b & 22.0 & 27.28 & -5.28 & -19.35 \\
4 & C-7 (O1-b) & 3.10 & 5.17 & -2.07 & -40.03 \\
5 & C-7 & 9.20 & 4.70 & +4.50 & +95.74 \\
\hline
\end{tabular}

Notes: a Recalculated using spot fire start position, resulting in $\mathrm{HROS}_{\mathrm{O}}$ of $4.8 \mathrm{~m} \cdot \mathrm{min}^{-1}$, absolute difference of $-0.74 \mathrm{~m}$ and relative difference of $-15.29 \%$; see Appendix A for details.

At Site 3, retardant lines (visible in Figure 5B) were clearly effective at stopping fire spread along the most active portion of the head. The resultant spread between A and B images was due to the escape of a portion of the flank (green line in Figure 6A).

Additional fire behaviour characteristics can sometimes be observed in these images and offer opportunities for measurement and documentation. The depth of the flaming front, for example, is often visible in non-forested fire images (e.g., Figure 6, image 3B). Figure 9 shows the flame front depth ranging from $4.76 \mathrm{~m}$ to $21.47 \mathrm{~m}$. The flame residence time [35] can also be calculated as the quotient of the flame front depth and HROS; for the latter example with a $27.28 \mathrm{~m} \cdot \mathrm{min}^{-1}$ spread rate, this was approximately $47 \mathrm{~s}$ using the average maximum fire front depth measurements from both images.

Many fires also exhibit short- or medium-range spotting (ember lofting; [36]), which can also potentially be studied using monoplotting. For Site 2, we identified the development of a secondary head caused by downwind spotting (Figure 10A) and measured the minimum spotting distance, assuming instantaneous ignition (298 m; Figure 10B). See also the Appendix A for a recalculation of HROS based on the spot fire positions. 


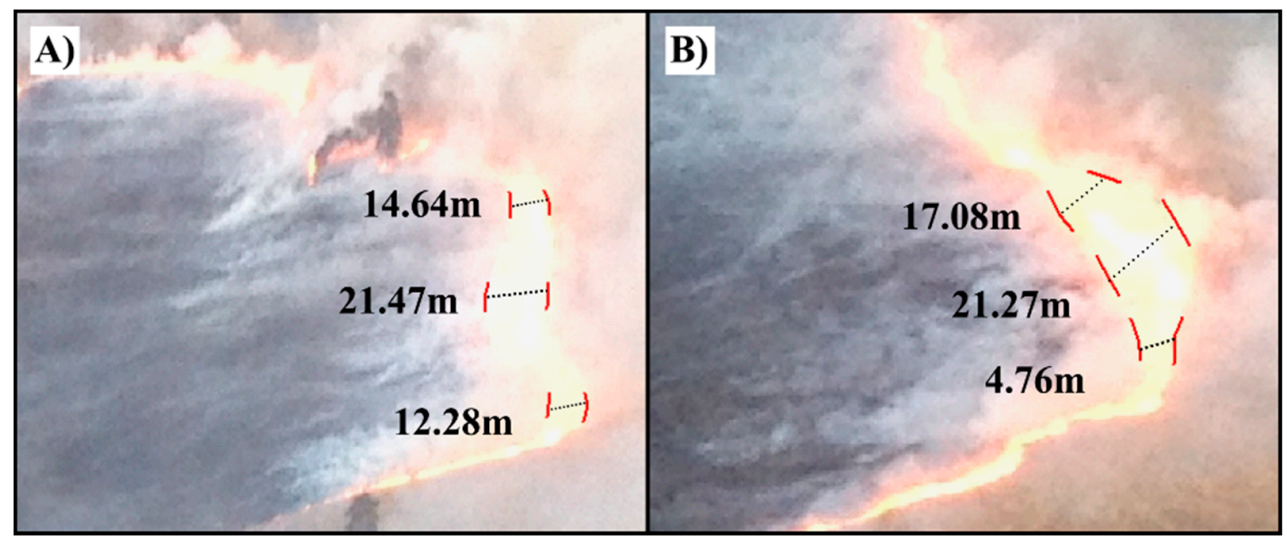

Figure 9. (A,B) Two flaming fronts in image 3B, displaying measurable flaming front depths (red).

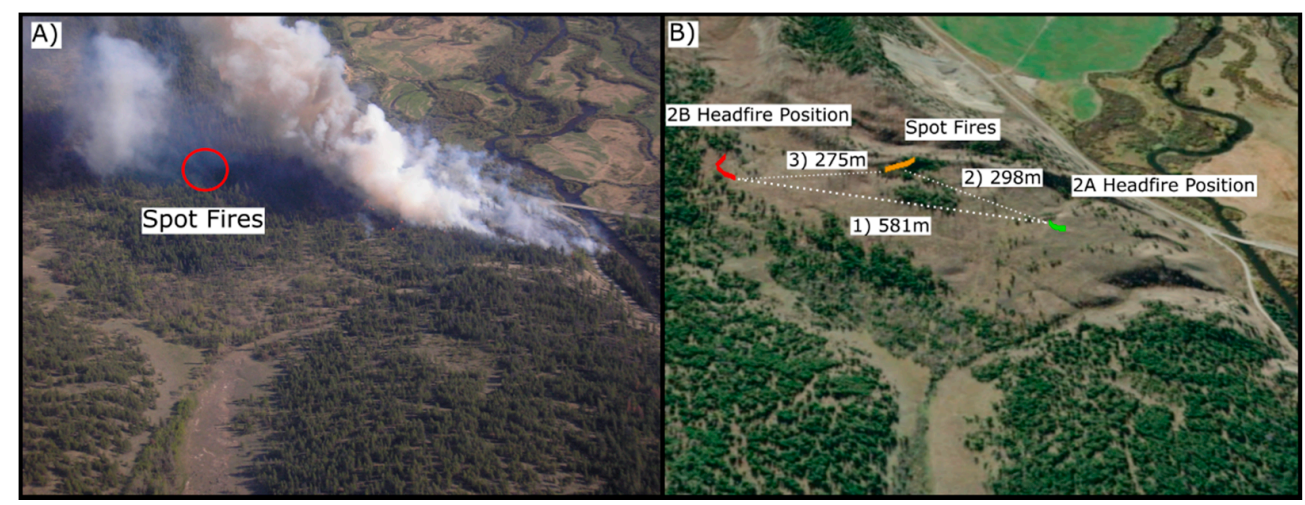

Figure 10. (A) Spot fires identified (red circle) on the Site 2 image at 18:16; (B) the headfire position at image 2A (green line), image 2B (red line) and the spot fire position (orange line); spread distances $(1,3)$ and minimum spotting distance (2) are as indicated.

\section{Discussion}

The goal of this study was to evaluate the use of monoplotting to geolocate the fire front position and estimate fire spread rates using oblique aerial photographs of wildfires. While the potential uses for this process are numerous, our main intention is to provide real world observations for validating and improving existing fire behaviour models. We made novel use of the monoplotting software program MPT to georeference image pairs from five wildfires, extracted fire front positions, and calculated the spread rate of the fire runs. While the process is only semi-automated (i.e., GCPs are selected and the fire front position is manually identified by a human interpreter), the systematic nature of the method should yield relatively reproducible results between users. Although skill in matching GCPs in the obliques and orthophotos, and in locating the fire front position will likely vary between individual interpreters, the method also provides an estimate of the angular and positional error of the GCPs that are indicative of the accuracy of each observation. The quality of our wildfire images and resolution of our orthoimages and DEM yielded good results; in our examples the total max 3D error of the observations ranged from 0.770 to $2.989 \mathrm{~m}$ with spread distances of 200 to $846 \mathrm{~m}$ resulting in max HROS errors of approximately $0.21-0.54 \%$, a very low degree of uncertainty for wildfire position data.

\subsection{Factors Affecting MPT Accuracy}

Previous research shows that the quality of the photographs, the angle of incidence of the camera and the resolution of the DEM and orthoimage used in the monoplotting process all influence the placement and precision of GCPs, and significantly affect the accuracy of a georeferenced image $[20,21,25,37]$. However, because these factors were very similar between our five sites, we were not able to evaluate their influence in this 
wildfire application. Rather, we examined the influence of landscape features, fuel type, distance of camera to the fire front position, camera elevation above ground level and camera angle of incidence (Tables 2 and 4). Our analysis suggests that the camera angle of incidence (determined by the distance between the camera and the image centre, the camera elevation above ground and ground slope in the DEM) strongly influenced the accuracy of georeferencing among 10 images, which is consistent with earlier work [21,23].

The visible landscape in all of our ten images provided sufficient GCP locations (5) for accurate georeferencing of the images. However, variation in the vegetation and landscape features in the images often influence the availability of GCPs. In our sites, open nonforested areas and areas of patchy forest in otherwise forested landscapes allowed for individual trees or shrubs to be identified in both the oblique images and orthoimages with a high degree of precision. The presence of built structures also provided precise GCPs, particularly building corners. It is apparent that heterogeneous landscapes will yield more precise GCPs than landscapes with continuous forest or grassland vegetation. Our tests on a range of fire photographs also suggested certain cases (not shown) where images were unsuitable or unreliable for analysis by monoplotting.

All wildfire images used in this study were taken from aircraft at moderate angles of incidence, which likely contributed to their level of accuracy (Table 4). This finding supports the relationship between angle of incidence and accuracy, because when the angle of incidence increases, the overall accuracy of the georeferenced image increases $[20,37]$. The angle of incidence is dependent on the position of the camera and the DEM at which it intersects; therefore, the angle of incidence can be heavily influenced by the terrain of the landscape present in the image, as well as the height and angle of obliquity of the camera when the image was taken. Due to this relationship, MPT works equally well in mountainous or flat areas, provided photographs are taken from a high vantage with a sufficiently oblique angle. For wildfire photography, this must be balanced with the obvious advantages of an unobstructed view of the flame front (see below). In our study, we observed that the mean 3D error increased as the angle of incidence decreased, but it is difficult to be certain that this had a significant impact on the accuracy of each image. Furthermore, the distance to fire front and elevation at which the wildfire images were captured in this study had varying influences on MPT accuracy. Relative to the other wildfire images, the camera closest to the fire front and at the lowest elevation above ground level resulted in the lowest mean 3D error out of all ten images. In general, the image resolution increased when the camera was closer to the fire front and at a lower elevation, which resulted in less pixelation while 'zooming in' on unique landscape features. This allowed the GCPs to be selected with greater precision, thus increasing the accuracy, a finding that is consistent with previous research [21]. However, in some cases, within the limits of the resulting image resolution, images with clearly identifiable GCPs, favourable fire front locations and high incidence angles may reduce the impact of the distance and elevation on MPT errors.

A unique challenge associated with monoplotting wildfire imagery involves the obscuring effect of the smoke plume on the fire head. Note that some authors have proposed a broader definition of the head that includes perimeter segments below the maximum ROS, e.g., greater than $50 \%$ of maximum ROS, for fireline communication and safety purposes [38]. Our focus, however, was on the single point of maximum fire intensity and ROS (in relatively homogenous fuels and topography). In very high angle (near-nadir) photographs, the position of the fire's head is often partly or fully hidden; this can undermine much of the precision gained from the high angle, as estimating fire front position in these cases can be highly subjective. A camera angle of incidence near -45 degrees, aimed underneath the smoke plume appears to be a good compromise. However, the best camera angle of incidence and position for a given fire will depend on the fire and plume behaviour, and, on some fires (e.g., surface fires with very strong winds and smoke plumes attached to the ground), identifying an accurate frontal position from photographs will be difficult. Confidence can be increased when multiple photographs show the fire 
head from different vantage points within a short time span (few seconds to $\sim 1-2 \mathrm{~min}$ ). Future studies will explore the use of infrared sensors and machine learning approaches to assist with tracing the fire front and perimeter on oblique wildfire imagery.

The final step in our exploratory analysis involved comparing spread rates estimated from the monoplotted fire position locations with FBP System predictions. Analyzing each fire run included best estimates of fire environment inputs given the available data. While the full details and sensitivity of these decisions are beyond the scope of this study, some details are provided in Appendix A. The error between predicted and observed spread rates in our fires ranged from $19 \%$ to $96 \%$, which is not unusual for a small number of observations, particularly slower-spreading surface fires in conifer stands [39]. Interestingly, three out of five examples were in fuel complexes most similar to the C-7 fuel type ('Ponderosa pine-Douglas-fir'), a less well-documented type in the FBP System [2]. Assuming a similar definition of HSD (i.e., the minimum Hausdorff distance between perimeters), differences between observed and predicted values can result from five sources: interpreter and methodological error in estimating the location of GCPs; interpreter error in observing or locating the true fire front position; unobserved processes such as spotting that occurs between photographs; model error in the prediction system (e.g., due to uncertainty in the spread model); and error in weather and fuel moisture inputs, particularly the wind speed and direction at the fire location. Other studies have discussed these uncertainties $[14,16,39]$, but they are not easily resolved post-hoc. It is not possible to have perfect knowledge of the condition of fuels and the state of the atmosphere affecting wildfire fronts. As we improve our techniques for measuring and characterizing the fire environment, so will we also improve our fire behaviour models, using methods such as those described here $[40,41]$.

\subsection{Recommendations for Future Research and Application}

Based on our experience with applying the monoplotting method to oblique aerial images of wildfires taken in the first few hours following an ignition, we recommend the following practices:

1. When selecting wildfire images for monoplotting, the fire front position must be visible or at least interpretable with a high degree of confidence and the visible landscape and resolution of the images must permit precise location of at least five GCPs. Monoplotting to determine the position of fire features will be most successful in heterogeneous landscapes. Accuracy may be higher in mountainous terrain.

2. The accuracy of georeferencing increases with the resolution of the available orthophotos and DEM as well as the distance from camera to ground and camera settings, which influence the pixel resolution. The monoplotting method will be more accurate in regions where orthophotos of half meter resolution and an underlying DEM of at least $25 \mathrm{~m}$ resolution are available (for very irregular terrain a DEM with higher resolution is recommended).

3. Images captured from close distance to the fire and at a lower elevation allow for more precise location of GCPs. However, this also reduces the field of view and may restrict the number of GCPs. We recommend a distance range between 650 and $2500 \mathrm{~m}$, and an elevation range of 350 to $1050 \mathrm{~m}$ to yield angles of incidence from about -30 to $-50^{\circ}$ and a good field of view and perspective of the fire front. Ideally, the view of the flaming front is unobscured by the smoke plume, although it is not always possible. Bird dog aircraft attached to air tanker groups are often in this airspace and can provide a good platform for acquiring wildfire spread imagery.

4. Care must be taken in locating fire fronts in oblique photos with regard to the depth of visible flame, the shape of the fire front, the location of the smoke plume base and direction of smoke spread; this requires some training and experience. Complex fire spread patterns, particularly when fuels or terrain are highly heterogeneous or spotting is a significant factor, may be georeferenced using monoplotting, but will be much more difficult to relate to the fire environment. Such considerations are beyond the scope of this article. 
Based on the success of this pilot study, we are currently expanding our research to obtain more wildfire spread observations from the historic database. Consideration should also be given to mounting dedicated cameras with overlapping IR sensors on operational aircraft that would capture imagery in a more systematic manner, such as georeferencing the standard image while extracting the fire front from the IR image. In addition, analysis of GIS tracking data on airtankers would provide insights into the field of view from the airtanker airspace [42].

With increasing severity and variability of wildfires, knowledge of wildfire behaviour has never been more important. Monoplotting of oblique air photos of wildfires, often acquired during the early stages of wildfire growth and response, can provide new and accurate fire spread observations to inform fire behaviour prediction or other aspects of wildland fire science.

Author Contributions: Conceptualization, D.D.B.P., S.W.T. and C.B. (Christopher Bone); methodology, H.H.; software, C.B. (Claudio Bozzini); writing—original draft preparation, H.H.; writingreview and editing, D.D.B.P., S.W.T., C.B. (Christopher Bone) and C.B. (Claudio Bozzini); supervision, C.B. (Christopher Bone) and D.D.B.P.; project administration, C.B. (Christopher Bone); funding acquisition, D.D.B.P. All authors have read and agreed to the published version of the manuscript.

Funding: This research was funded by the Natural Resources Canada-Canadian Forest Service's Emergency Management System program as a grant under Account 51574-58300.

Institutional Review Board Statement: Not applicable.

Informed Consent Statement: Not applicable.

Data Availability Statement: The data that support this study were obtained in part from the BC Wildfire Service by permission. Data will be shared upon reasonable request to corresponding author with permission from the BC Wildfire Service.

Acknowledgments: The authors wish to thank the BC Provincial Air Tanker Centre for the archive of aerial wildfire images and Patrick Day at GeoBC/FLNRORD for the LiDAR and Orthoimage access. Thanks are also extended to Chris Stockdale and Claudio Bozzini for hosting a MPT training course in Edmonton, AB, Canada and for their continued support regarding MPT troubleshooting. Finally, we would like to thank the three anonymous reviewers whose comments improved the manuscript as well as Rick Lanoville for his passion and original ideas on wildfire image analysis.

Conflicts of Interest: The authors declare no conflict of interest. The funders had no role in the design of the study; in the collection, analyses, or interpretation of data; in the writing of the manuscript, or in the decision to publish the results.

\author{
Abbreviations \\ The following abbreviations are used in this manuscript: \\ BCWS British Columbia Wildfire Service \\ BUI Buildup Index \\ DEM Digital Elevation Model \\ FBP Canadian Fire Behaviour Prediction System \\ FFMC Fine Fuel Moisture Code \\ FWI Canadian Forest Fire Weather Index System \\ GCP Ground Control Point \\ GIS Geographic Information System \\ HROS Head Fire Rate of Spread \\ ISI Initial Spread Index \\ LST Local Standard Time \\ MPT WSL Monoplotting Tool \\ PATC Provincial Air Tanker Centre \\ HSD Geodesic Head Fire Spread Distance \\ VRI Vegetation Resource Inventory
}




\section{Appendix A. Summary of Canadian Fire Behaviour Prediction System Calculations}

The main data used to calculate HROS for conifer forests in the FBP System presented in Tables 6 and A1 include the following inputs: Fuel type, ISI, BUI and foliar moisture content; degree of curing is also included for the grass fuel type. ISI in turn is calculated and adjusted to represent the effect of slope relative to wind on spread based on the Fine Fuel Moisture Code (FFMC), wind speed and direction, slope and slope azimuth. We determined the fuel type at the fire locations from the $\mathrm{BC}$ provincial forest inventory layers (fuel structure and FBP fuel type; [33] and the slope and slope azimuth from the DEM. The daily FFMC and BUI were obtained from a dataset of FWI System station observations interpolated to fire locations using procedures in [34]. Values interpolated from several weather stations were used because fires can be up to $50 \mathrm{~km}$ or more from the nearest station. However, we used the wind speed and direction observed at the nearest hour to the time of the photographs at the nearest BC Wildfire Service weather station and the interpolated daily FFMC to calculate ISI, which was then adjusted for slope effects. All calculations were completed using RedApp 6.2.4, a software developed by the RedApp Development Team in Canada [43]. We made a number of modifications to the general procedure to reflect local site conditions and data availability for Sites 1-3 as follows:

Site 1. The fuel type at this location consisted of subalpine conifer forest of Engelmann spruce and subalpine fir. Fire behaviour analysts in $B C$ have observed that fire spread in these stands tends to behave somewhere between the predictions of the C-3 and C-2 fuel types, thus we used the mean of the predicted HROS for C-2 and C-3.

Site 2. After completing the main analysis, we noted spot fires $\sim 300 \mathrm{~m}$ from the main flame front that may have influenced the spread pattern between images; this would result in a much lower spread distance and HROS than originally predicted. Spotting to $300 \mathrm{~m}$ is close to the prediction (RedApp's implementation of Albini's model; [44]) of intermediaterange spotting distance of 340-360 $\mathrm{m}$ from a surface fire (assuming downwind cover height of $15-20 \mathrm{~m}$ and wind speed of $18.5 \mathrm{~km} \cdot \mathrm{h}^{-1}$ ). According to the Alexander and Cruz spotting separation distance model [45], ember transport distances of $46-89 \mathrm{~m}$ would be required to allow a new front to develop and spread that would not be overrun by the main flame front (Calculations assume an ignition delay (ID) of 1-10 min, acceleration coefficient $\left(a_{a}\right)$ of 0.115 , observed HROS (assuming fire spread from the spot fires) of $4.84 \mathrm{~m} \cdot \mathrm{min}^{-1}$ and steady state buildup time ( $T_{\mathrm{ss}}$ ) of $30 \mathrm{~min}$ ). Thus, we assume that the Site 2 spot fires would generate a new independent front, and so we used their position to estimate HROS. The spread rate based on the spot fire position $\left(4.8 \mathrm{~m} \cdot \mathrm{min}^{-1}\right)$ is much closer to the C-7 HROS prediction $\left(4.1 \mathrm{~m} \cdot \mathrm{min}^{-1}\right)$.

Site 3. This fire was less than $10 \mathrm{~km}$ and at a similar elevation to a nearby weather station; therefore, we used the hourly FFMC from that station rather than the interpolated daily FFMC.

We further note that the Site 4 fire spread through open grassland on the lower slope before spreading uphill into the very open Douglas-fir (C-7) stand. Although the analyzed fire run only encompasses the forested portion of the slope, the fire environment is complex, making estimation of FBP System inputs challenging. The fire environment includes a steep slope with changing aspect, heterogeneous fuels and a significant body of water directly below the slope (the Fraser River). Furthermore, nearby weather stations are more than $40 \mathrm{~km}$ away and show different wind directions during the fire run. Considering these factors, the $40 \%$ discrepancy between predicted and observed HROS (Table 6 ) seems quite good. Alternative methods for estimating wind speed affecting fires could include use of the length to breadth ratio [46] or using terrain-influenced wind models (e.g., [47]), although these methods were not explored here.

Despite their importance, there are few validation studies of fire behaviour models. In particular, further evaluation of the C-7 fuel type may be merited, as this type is based on relatively few data points [2]. Monoplotting can be useful in providing precise and unbiased estimates of the fireline position at different times. Estimating fire environment 
inputs is a necessary task in these efforts that can range from simple to complex depending on the circumstance.

Table A1. Fire environment inputs and predicted headfire rate of spread for five example fires. ISIsw is the slope-wind adjusted ISI; and $\mathrm{HROS}_{\mathrm{p}}$ is the predicted rate of spread.

\begin{tabular}{|c|c|c|c|c|c|c|c|c|c|}
\hline Site \# & FFMC & $\begin{array}{l}\text { Wind Speed } \\
\left(\mathrm{km} \cdot \mathrm{h}^{-1}\right)\end{array}$ & $\begin{array}{l}\text { Wind } \\
\text { Observation } \\
\text { (LST) }\end{array}$ & $\begin{array}{c}\text { Distance } \\
(\mathbf{k m})\end{array}$ & $\begin{array}{c}\text { Slope, } \\
\text { Azimuth }\end{array}$ & $\mathrm{ISI}_{\mathrm{sw}}$ & BUI & Fuel Type & HROS $_{p}$ \\
\hline 1 & 89.0 & 14.5 & 1500 & 23 & $<5 \%$ & 7.7 & 57 & $C-2, C-3^{a}$ & 5.8 \\
\hline 2 & 91.0 & 18.5 & 1900 & 28 & $<5 \%$ & 12.6 & 42 & C-7 & $4.1^{\mathrm{b}}$ \\
\hline 3 & $93.6^{c}$ & $1.8^{\mathrm{d}}$ & 1900 & 9 & $<5 \%$ & 7.9 & - & $\mathrm{O}-1 \mathrm{~b}$ & 22.0 \\
\hline 4 & 94.0 & $7.7^{\mathrm{e}}$ & 1500 & 46 & $32 \%, 215^{\mathrm{e}}$ & 10.0 & 94 & $\underset{\mathrm{e}}{\mathrm{C}-7 \mathrm{(O}-1 \mathrm{~b})}$ & 3.1 \\
\hline 5 & 95.0 & 16.1 & $1400-1500^{\mathrm{f}}$ & 25 & $<5 \%$ & 19.5 & 146 & C-7 & 9.2 \\
\hline
\end{tabular}

Notes: ${ }^{a}$ Used 'dual-fuel' concept; ROSP is calculated from $50 \%$ of each C-2, C-3 $\left(9.0 \mathrm{~m} \cdot \mathrm{min}^{-1}, 2.6 \mathrm{~m} \cdot \mathrm{min}^{-1}\right)$; ${ }^{\mathrm{b}}$ Using spot fire location as a starting point; see text for details; ${ }^{\mathrm{c}}$ Weather station was $<10 \mathrm{~km}$ from fire and in the same valley; therefore, station hFFMC was used; ${ }^{\mathrm{d}}$ Smoke plume characteristics suggest higher wind speed at the fire than at the station; ${ }^{\mathrm{e}}$ Variable wind speed and direction, aspect, wind-slope vectoring and heterogeneous fuel type; ROSp was based on a single wind speed and direction $\left(3^{\circ}\right)$ and single fuel type (C-7);

${ }^{\mathrm{f}}$ Wind speed used was average of 1400 and 1500 (LST) readings.

\section{References}

1. Taylor, S.W.; Woolford, D.G.; Dean, C.B.; Martell, D.L. Wildfire Prediction to Inform Fire Management: Statistical Science Challenges. Stat. Sci. 2013, 28, 586-615. [CrossRef]

2. Forestry Canada Fire Danger Group. Development and structure of the Canadian Forest Fire Behavior Prediction System, Information Report ST-X-3; Forestry Canada, Science and Sustainable Development Directorate: Ottawa, ON, Canada, 1992.

3. Johnston, L.M.; Wang, X.; Erni, S.; Taylor, S.W.; McFayden, C.B.; Oliver, J.A.; Stockdale, C.; Christianson, A.; Boulanger, Y.; Gauthier, S.; et al. Wildland fire risk research in Canada. Environ. Rev. 2020, 28, 164-186. [CrossRef]

4. Parisien, M.A.; Dawe, D.A.; Miller, C.; Stockdale, C.A.; Armitage, O.B. Applications of simulation-based burn probability modelling: A review. Int. J. Wildl. Fire 2019, 28, 913. [CrossRef]

5. Wotton, B.M.; Alexander, M.E.; Taylor, S.W. Updates and Revisions to the 1992 Canadian Forest Fire Behavior Prediction System, GLC-X-10; Natural Resources Canada, Canadian Forest Service, Great Lakes Forestry Centre: Sault St. Marie, ON, Canada, 2009.

6. Plucinski, M.P.; Sullivan, A.L.; Rucinski, C.J.; Prakash, M. Improving the reliability and utility of operational bushfire behaviour predictions in Australian vegetation. Environ. Model. Softw. 2017, 91, 1-12. [CrossRef]

7. Hirsch, K. Canadian Forest Fire Behavior Prediction (FBP) System: User's Guide; Northern Forestry Centre: Edmonton, AB, Canada, 1996.

8. Van Wagner, C.E. Development and Structure of the Canadian Forest Fire Weather Index System; Canadian Forestry Service: Ottawa, ON, Canada, 1987.

9. Alexander, M.E.; Stocks, B.J.; Lawson, B.D. Fire Behavior in Black Spruce-Lichen Woodland: The Porter Lake project, Information Report NOR-X-310; Northern Forestry Centre, Northwest Region, Forestry Canada: Edmonton, AB, Canada, 1991.

10. Stocks, B.J. Fire behavior in mature jack pine. Can. J. For. Res. 1989, 19, 783-790. [CrossRef]

11. Alexander, M.E.; Thomas, D.A. Wildland fire behavior case studies and analyses: Value, approaches, and practical uses. Fire Manag. Today 2003, 63, 4-8.

12. Allison, R.S.; Johnston, J.M.; Craig, G.; Jennings, S. Airborne optical and thermal remote sensing for wildfire detection and monitoring. Sensors 2016, 16, 1310. [CrossRef]

13. Moriarty, K.; Cheng, A.S.; Hoffman, C.M.; Cottrell, S.P.; Alexander, M.E. Firefighter Observations of 'Surprising' Fire Behavior in Mountain Pine Beetle-Attacked Lodgepole Pine Forests. Fire 2019, 2, 34. [CrossRef]

14. Filkov, A.; Duff, T.; Penman, T. Improving Fire Behaviour Data Obtained from Wildfires. Forests 2018, 9, 81. [CrossRef]

15. Alexander, M.E.; Cruz, M.G. Are the applications of wildland fire behaviour models getting ahead of their evaluation again? Environ. Model. Softw. 2013, 41, 65-71. [CrossRef]

16. Gould, J.; McCaw, M.; Cruz, M.; Anderson, W. How good are fire behaviour models? Validation of eucalypt forest fire spread model. In Proceedings of the Wildland Fire Conference, Sun City, South Africa, 9-13 May 2011.

17. Sullivan, A.L. Wildland surface fire spread modelling, 1990-2007. 2: Empirical and quasi-empirical models. Int. J. Wildl. Fire 2009, 18, 369-386. [CrossRef]

18. Perrakis, D.B.; Lanoville, R.A.; Taylor, S.W.; Hicks, D. Modeling wildfire spread in mountain pine beetle-affected forest stands, British Columbia, Canada. Fire Ecol. 2014, 10, 10-35. [CrossRef]

19. Makarovic, B. Digital Monoplotters. ITC J. 1973, 4, 583-600.

20. Bozzini, C.; Conedera, M.; Krebs, P. A New Monoplotting Tool to Extract Georeferenced Vector Data and Orthorectified Raster Data from Oblique Non-Metric Photographs. Int. J. Herit. Digit. Era 2012, 1, 499-518. [CrossRef] 
21. Stockdale, C.A.; Bozzini, C.; Macdonald, S.E.; Higgs, E. Extracting ecological information from oblique angle terrestrial landscape photographs: Performance evaluation of the WSL Monoplotting Tool. Appl. Geogr. 2015, 63, 315-325. [CrossRef]

22. Monoplotting Tool. Available online: https://www.wsl.ch/monoplotting (accessed on 18 October 2021).

23. Conedera, M.; Bozzini, C.; Ryter, U.; Bertschinger, T.; Krebs, P. Using the Monoplotting Technique for Documenting and Analyzing Natural Hazard Events. In Natural Hazards: Risk Assessment and Vulnerability Reduction; IntechOpen: London, UK, 2018; pp. 107-108. [CrossRef]

24. Bozzini, C. WSL Monoplotting Tool: User Manual; Swiss Federal Research Institute WSL: Birmensdorf, Switzerland, 2018.

25. Steiner, L. Reconstruction of Glacier States from Geo-Referenced, Historical Postcards. Master's Thesis, Institut für Kartographie und Geoinformatik, Hannover, Germany, 2012.

26. Schenk, T. Introduction to Photogrammetry; Department of Civil and Environmental Engineering and Geodetic Science, The Ohio State University: Columbus, Ohio, USA, 2005; pp. 59-61.

27. Wildfire Season. 2017. Available online: https://www2.gov.bc.ca/gov/content/safety/wildfire-status/about-bcws/wildfirehistory/wildfire-season-summary (accessed on 7 July 2021).

28. BC Data Catalogue. Available online: https:// catalogue.data.gov.bc.ca/dataset?tags=VRI (accessed on 1 January 2020).

29. ESRI World Imagery (For Export). Available online: https://www.arcgis.com/home/item.html?id=226d23f076da478bba4589e7 eae95952 (accessed on 1 January 2020).

30. Weber, R.O. Analytical models for fire spread due to radiation. Combust. Flame. 1989, 78, 398-498. [CrossRef]

31. van Wagner, C.E. A simple fire-growth model. For. Chron. 1969, 45, 103-104. [CrossRef]

32. Cheney, N.P.; Gould, J.S. Fire Growth in grassland fuels. Int. J. Wildland Fire. 1995, 5, 237-247. [CrossRef]

33. Perrakis, D.B.; Eade, G.; Hicks, D. British Columbia Wildfire Fuel Typing and Fuel Type Layer Description, Information Report BC-X-444; Pacific Forestry Centre: Victoria, BC, Canada, 2018.

34. Nadeem, K.; Taylor, S.W.; Woolford, D.G.; Dean, C.B. Mesoscale spatiotemporal predictive models of daily human- and lightningcaused wildland fire occurrence in British Columbia. Int. J. Wildl. Fire 2019, 29, 11-27. [CrossRef]

35. Wotton, B.M.; Gould, J.S.; McCaw, W.L.; Cheney, N.P.; Taylor, S.W. Flame temperature and residence time of fires in dry eucalypt forest. Int. J. Wildl. Fire 2012, 21, 270-281. [CrossRef]

36. Werth, P.A.; Potter, B.E.; Alexander, M.E.; Clements, C.B.; Cruz, M.G.; Finney, M.A.; Forthofer, J.M.; Goodrick, S.L.; Hoffman, C.; Jolly, W.M.; et al. Synthesis of Knowledge of Extreme Fire Behavior: Volume 2 for Fire Behavior Specialists, Researchers, and Meteorologists. Gen. Tech. Rep. PNW-GTR-891; Pacific Northwest Research Station, Forest Service, U.S. Department of Agriculture: Portland, OR, USA, 2016.

37. Gabellieri, N.; Watkins, C. Measuring long-term landscape change using historical photographs and the WSL Monoplotting Tool. Landsc. Hist. 2019, 40, 93-109. [CrossRef]

38. Planas, E.; Cubells, M.; Pastor, E. Different approaches for the head fire perimeter definition in wildland fires. Fire. Saf. Sci. 2011, 10, 1425-1435. [CrossRef]

39. Cheney, N.P.; Gould, J.S.; McCaw, W.L.; Anderson, W.R. Predicting fire behaviour in dry eucalypt forest in southern Australia. For. Ecol. Manage. 2012, 280, 120-131. [CrossRef]

40. Albini, F.A.; Anderson, E.B. Predicting fire behavior in US Mediterranean ecosystems. Gen. Tech. Rep. PSW-GTR-58. In Proceedings of the Symposium on Dynamics and Management of Mediterranean-Type Ecosystems, San Diego, CA, USA, 22 June 1981; Pacific Southwest Forest and Range Experiment Station, Forest Service, U.S. Department of Agriculture: Berkeley, CA, USA, 1982; pp. 483-489.

41. Finney, M. Efforts at Comparing Simulated and Observed Fire Growth Patterns. Final Report INT-95066-RJVA; USDA Forest Service, Rocky Mountain Research Station, Fire Science Laboratory: Missoula, MT, USA, 2000.

42. Clark, N.A.; Martell, D.L. The use of aircraft tracking GPS data to develop models of the use of airtankers in forest fire management. INFOR 2021, 57, 535-562. [CrossRef]

43. The Universal Fire Behaviour Calculator. Available online: https://redapp.org/ (accessed on 18 October 2021).

44. Albini, F.A. Potential Spotting Distance from Wind-Driven Surface Fires. Res. Pap. INT-309; Intermountain Forest and Range Experiment Station, Forest Service, U.S. Department of Agriculture: Ogden, UT, USA, 1983.

45. Alexander, M.E.; Cruz, M.G. Evaluating a model for predicting active crown fire rate of spread using wildfire observations. Can. J. For. Res. 2006, 36, 3015-3028. [CrossRef]

46. Taylor, S.W.; Alexander, M.E. Field guide to the Canadian Forest Fire Behavior Prediction (FBP) System, 3rd ed.; Northern Forestry Centre, Canadian Forest Service: Edmonton, AB, Canada, 2018.

47. Forthofer, J.M.; Butler, B.W.; Wagenbrenner, N.S. A comparison of three approaches for simulating fine-scale surface winds in support of wildland fire management. Part I. Model formulation and comparison against measurements. Int. J. Wildl. Fire 2014, 23, 969-981. [CrossRef] 